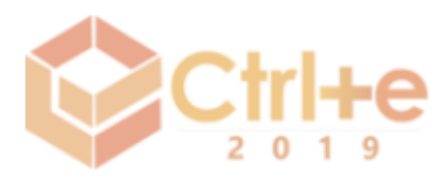

IV Congresso sobre Tecnologias na Educação (Ctrl+E 2019)

Recife, Pernambuco - Brasil

28 a 30 de agosto de 2019

\title{
Oficina de Apoio a Resolução de Problemas e Lógica Computacional utilizando a Computação Desplugada e Gamificação
}

\author{
José Vinnicius dos Santos Oliveira1, Larrysa Mirelly Rosendo Figueiredo 1, Flávia \\ Veloso Costa Souza 1
}

\begin{abstract}
1 Departamento de Ciências Exatas - Universidade Federal da Paraíba Rua da Mangueira, s/n, Companhia de Tecidos Rio Tinto 58.297-000 - Rio Tinto - PB - Brasil

\{vinnicius.santos, larrysa.mirelly, flavia\}@dce.ufpb.br
\end{abstract}

\begin{abstract}
This article presents the results obtained with DespluGames workshop application, held within the scope of PIBID-Informatica (Institutional Program of Scholarships for Initiation to Teaching), which aimed to analyze the efficiency of existing applicability between methodologies of unplugged computing and gamification in the introductory teaching of programming for high school students. The workshop used the concept of block programming to promote student learning in the early principles of computer programming logic.
\end{abstract}

Resumo. Este artigo apresenta os resultados obtidos com a aplicação da oficina DespluGames, realizada no âmbito do PIBID - Informática (Programa Institucional de Bolsas de Iniciação à Docência), que teve como objetivo analisar a eficiência da aplicabilidade concomitante das metodologias de Computação Desplugada e elementos de Gamificação no ensino introdutório de lógica de programação para alunos do ensino médio. A oficina empregou o conceito de programação em blocos para promover o aprendizado dos alunos nos conceitos iniciais da lógica de programação de computadores.

\section{Introdução}

A revolução digital, está a cada dia mais inserida no cotidiano da sociedade e com ela, um crescimento exponencial na quantidade de dispositivos tecnológicos, utilizados diariamente em diversas atividades. Essa revolução, trouxe para a sociedade novas formas de comunicação, de produção e de aprendizagem. Diante dessas mudanças novas competências vêm sendo demandadas, tais quais resolução de problemas, aprendizado contínuo ao longo da vida, e capacidade de trabalhar em equipe.

Aprender a programar é uma competência que dá suporte para as pessoas desenvolverem soluções fáceis e rápidas para problemas diversos. Aprender programação é de suma importância para a Computação [Scaico et al., 2012]]. Segundo [Valente, 2016], é importante que seja dada ênfase ao ensino de conceitos computacionais no processo de inserção da ciência da computação na Educação Básica no Brasil. Objetivase, com essa inserção, oportunizar a formação de habilidades e competências computacionais, apoiando a ciência e suas áreas de conhecimento [SBC, 2017]. 
Na literatura da área de Educação em Computação, são encontradas pesquisas que têm sido realizadas utilizando a Computação Desplugada para apoiar o ensino de lógica de programação e desenvolver o Pensamento Computacional. De acordo com [Bell et al, 2011] a Computação Desplugada pode desenvolver o raciocínio lógico dos alunos, estimular a resolução de problemas e a criatividade em um contexto significativo. [Marques, 2011] aponta a Computação Desplugada como uma forma de promover o engajamento e aumentar o interesse do aluno no aprendizado de programação.

Este trabalho apresenta os resultados da oficina DespluGames, realizado no âmbito do PIBID - Computação, para alunos do $1^{\circ}$ ano do curso técnico de Manutenção de Sistemas da Informação da Escola Cidadã Integral e Técnica João da Matta Cavalcantti de Albuquerque, situada na cidade de Mamanguape - PB. O objetivo era apresentar conceitos de lógica de programação de forma intuitiva e despertar o interesse e compreensão dos alunos na resolução de problemas reais. Durante a oficina buscou-se unir a Computação Desplugada e elementos de Gamificação para engajar os alunos.

\section{Computação Desplugada e Gamificação no ensino de Lógica de Programação}

Para subsidiar as discussões que serão apresentadas neste trabalho, elegemos como aporte teórico trabalhos relacionados aos temas sobre o âmbito da Educação, Aprendizagem, Computação Desplugada e Gamificação, destacando a importância das mesmas e o papel dos educadores e discentes; e a utilização de um novo método no cenário educacional.

Nos últimos anos a Computação Desplugada tem sido vista como um método que pode contribuir no ensino e aprendizagem de conceitos da Ciência da Computação. Segundo [Bell et al., 2011] a Computação Desplugada é um conjunto de atividades lúdicas desenvolvidas com a finalidade de ensinar conceitos da área de computação sem o uso de computadores e sem aprofundamento nos detalhes técnicos. A Computação Desplugada pode ser utilizada em qualquer nível educacional e com as mais diversas faixas etárias.

Pesquisa realizada por [Bordini et. al., 2016] apresenta o estado da arte relativa a disseminação do Pensamento Computacional no Brasil. Em relação ao método da Computação Desplugada, os resultados apresentados apontam para o uso, em sua maioria, das atividades provenientes do livro Computer Science Unplugged proposto por Tim Bell, Ian H. Witten e Mike Fellows [Bell et al., 2011]. De forma espontânea e demonstrando ser um método bastante eficiente, a Computação Desplugada vem possibilitar o estímulo ao Pensamento Computacional que por sua vez permite ao educando aprender de modo descomplicado os conceitos da computação [Ferreira et al. 2015].

A Gamificação (Gamification) ou Ludificação, segundo [Alves, 2015], é um método que tem o intuito de possibilitar a incorporação de técnicas, características e mecânica dos jogos em atividades do mundo real não vinculadas a games. Tendo como meta, estimular as participações voluntárias dos aprendizes, incentivar o diálogo entre os alunos e maximizar o engajamento pessoal do aprendiz, visando assim a superação de algumas das dificuldades inerentes ao processo educacional. Para isso, é proposto a utilização de mecânicas e lógicas de games para estimular competitividade saudável, gerar sentimento de conquista, desejo de contínuo avanço nas novas fases do estudo. A 
Gamificação possibilita a mensuração constante de desempenho e torna o aprendizado mais envolvente, aprazível e desafiador [Braga e Obregon, 2015].

Desta forma, percebe-se o potencial da Gamificação no processo de ensino e aprendizagem. Este trabalho propõe o uso de atividades desplugadas alinhadas com técnicas de Gamificação com o objetivo de apoiar o desenvolvimento da habilidade de resolução de problemas e o ensino de lógica de programação, utilizando atividades lúdicas adaptadas.

\section{Planejamento da oficina DespluGames}

Inicialmente foi realizado um estudo diagnóstico com o objetivo de conhecer a realidade escolar e as necessidades que envolvem os alunos, identificando fatores relevantes que poderiam contribuir e interferir nas práticas pedagógicas. Em um segundo momento foi feito um levantamento de atividades desplugadas existentes e proposta a adaptação de atividades para serem aplicadas com os alunos do primeiro ano do curso de técnico de Manutenção de Sistemas da Informação, buscando atender as necessidades e contexto dos mesmos.

A oficina DespluGames é uma iniciativa do Programa Institucional de Bolsas de Iniciação à Docência (PIBID) do curso de Licenciatura em Ciência da Computação da UFPB. A oficina foi planejada para acontecer em dois encontros presenciais com duração de 1 hora e 30 minutos cada. Para a oficina foram planejados desafios para serem resolvidos em equipe. A cada novo conceito (funções, comandos de repetição e tomadas de decisão) era apresentado para as equipes dois novos desafios.

Dessa forma, a oficina foi planejada da seguinte maneira: (I) Apresentação dos conceitos, (II) Apresentação e execução dos desafios, (III) Discussão de estratégias em grupo e (IV) Resolução do desafio apresentado. As equipes tinham um tempo máximo que variava entre 5 - 15 minutos dependendo do nível do desafio. O Quadro 1 apresenta todos os desafios utilizados na oficina e os conteúdos trabalhados em cada um deles.

Quadro 1 - Desafios utilizados na oficina DespluGames

\begin{tabular}{|c|c|c|c|c|}
\hline Dias & Desafios & Conteúdos & Nível & Descrição \\
\hline Dia 1 & Andar no labirinto & Funções. & Fácil & $\begin{array}{l}\text { Utilizar funções como } \\
\text { andar e virar à direita, } \\
\text { virar à esquerda para } \\
\text { chegar ao objetivo }\end{array}$ \\
\hline Dia 1 & $\begin{array}{l}\text { Verificar a existência de } \\
\text { favos de mel. } \\
\text { Produzir mel. }\end{array}$ & $\begin{array}{l}\text { Tomadas de Decisão } \\
\text { (se, senão se e senão) }\end{array}$ & Fácil & $\begin{array}{l}\text { Utilizar os blocos se } \\
\text { para verificar se existe } \\
\text { favos no piso atual. }\end{array}$ \\
\hline Dia 2 & $\begin{array}{l}\text { Andar, remover e colocar } \\
\text { pontos de produção de } \\
\text { mel. Produzir mel. }\end{array}$ & $\begin{array}{l}\text { Comandos de } \\
\text { repetição (enquanto e } \\
\text { para) }\end{array}$ & Intermediário & $\begin{array}{l}\text { Utilizar comandos de } \\
\text { repetição para preencher } \\
\text { buracos e remover terra } \\
\text { de montes. }\end{array}$ \\
\hline Dia 2 & Desafio Final & Todos & Difícil & $\begin{array}{l}\text { Utilizar funções, } \\
\text { repetição e decisões } \\
\text { para realizar uma } \\
\text { sequência de itens em } \\
\text { um mapa. }\end{array}$ \\
\hline
\end{tabular}

Fonte: Os autores. 
Buscando promover o envolvimento e motivar os alunos participantes da oficina utilizamos os seguintes elementos de Gamificação: Objetivos e regras claras, sistema de feedback, sistema de recompensas e competição. O Quadro 2 apresenta a característica do comportamento proposto por [Huizinga, 1980] e seu uso na oficina. Para armazenar as pontuações das equipes, foi desenvolvido um sistema simples de scoreboard, que chamamos de pódio. Um ranking era projetado na sala de aula para incentivar os alunos a chegarem no topo.

Quadro 2: Comportamento das características de Huizinga na oficina DespluGames

\begin{tabular}{|l|l|}
\hline Características de Huizinga & Comportamento na oficina \\
\hline $\begin{array}{l}\text { Objetivos: o jogo possui objetivo definido } \\
\text { e claro. }\end{array}$ & $\begin{array}{l}\text { Cada equipe deveria realizar os desafios apresentados, } \\
\text { dentro do tempo determinado. }\end{array}$ \\
\hline $\begin{array}{l}\text { Regras claras: para alcançar a meta, deve- } \\
\text { se agir de acordo com as regras } \\
\text { determinadas. }\end{array}$ & $\begin{array}{l}\text { As equipes eram informadas sobres as limitações para se } \\
\text { atingir o objetivo (tempo, forma de usar as peças, } \\
\text { pontuação). }\end{array}$ \\
\hline $\begin{array}{l}\text { Sistema de feedback (resultados): Avalia } \\
\text { as ações do jogador e o quanto ele está } \\
\text { próximo de alcançar o objetivo. }\end{array}$ & $\begin{array}{l}\text { As ações das equipes na resolução dos desafios eram } \\
\text { acompanhadas e feedbacks eram dados a equipe; a cada } \\
\text { término de um desafio, a equipe tinha uma visão sobre o } \\
\text { seu desempenho. }\end{array}$ \\
\hline $\begin{array}{l}\text { Sistema de recompensa e Competição: } \\
\text { receber bonificações de acordo com os } \\
\text { avanços. }\end{array}$ & $\begin{array}{l}\text { A primeira equipe que completasse o desafio corretamente } \\
\text { ganhava 10 pontos e as demais que conseguissem } \\
\text { completar o desafio ganhavam 5 pontos. }\end{array}$ \\
\hline
\end{tabular}

Fonte: Os autores.

\subsection{Elaboração do "BlockCode"}

Na elaboração da oficina foi proposto um quebra-cabeça para ser montado a partir da resolução de desafios em um labirinto adaptado do Code.org1. O "BlockCode", quebra-cabeça proposto, é um jogo que consiste na resolução de desafios que devem ser solucionados a partir da criação de algoritmos. Nessa atividade o aluno desenvolve habilidades tais quais abstração, raciocínio lógico e simulação.

Para a construção dos desafios foram utilizados os conteúdos que foram trabalhados na oficina. Todo material foi idealizado de forma lúdica, a fim de melhorar e preservar a atenção dos alunos ao conteúdo.

As peças que faziam parte do jogo foram produzidas seguindo o padrão do Code.org e Scratch2. Cada tipo de peça, conforme Imagem 1, possuía uma cor diferente e formatos que se encaixavam, como quebra-cabeças para preservar o sentido de fluxo de execução. Foram produzidas peças representando variáveis, funções e estruturas padrões nas linguagens de computação, estas foram impressas em papel adesivo e em formato de peças encaixáveis. Foram entregues para cada equipe fichas onde a resolução dos desafios deveria ser colada. 


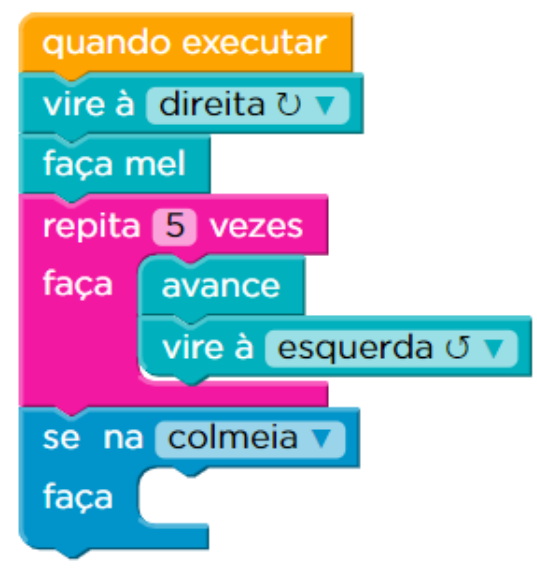

Figura 1 - Exemplo de uso das peças do quebra-cabeça "BlockCode"

\section{Resultados e Discussão}

A oficina foi realizada nos dias 30/05 e 13/06 de 2019, envolvendo 45 alunos do $1^{\circ}$ ano do Curso técnico em Manutenção de Sistemas da Informação da Escola Cidadã Integral e Técnica João da Matta Cavalcantti. Os alunos participantes não tinham um conhecimento básico de programação. Alguns já tinham ouvido sobre programação, mas não tinham tido contato prévio com lógica de programação. Para a realização dos desafios utilizando o "BlockCode" os alunos organizaram-se em seis (06) equipes, toda a escolha dos membros fora feita pelos mesmos.

Alguns alunos, na apresentação da oficina e dos primeiros conceitos trabalhados, demonstraram receio por ser o primeiro contato deles com programação. Porém quando as funções apresentadas foram demonstradas utilizando o "BlockCode" foi nítido o aumento no engajamento dos alunos nas atividades da oficina.

Durante a resolução dos desafios os integrantes das equipes mostraram-se participativos, notou-se uma comunicação e empenho dentro das equipes para a resolução dos mesmos. A cada desafio a equipe vencedora vibrava por sua conquista. As equipes que estavam no topo do ranking, criaram uma competição entre si para alcançar o topo do scoreboard.

No segundo dia da execução da oficina, os alunos já estavam acostumados com o método e a competição ficou mais acirrada, ao término do desafio final, no qual o mesmo daria a vitória a uma das equipes, veio o empate por duas delas no ranking. Foi necessário a realização de um novo desafio para que houvesse o desempate, para eles, era essencial que apenas uma equipe obtivesse o $1^{\circ}$ lugar.

Todos os desafios foram realizados de forma desplugada. Durante a resolução os monitores também forneciam suporte e tiravam dúvidas das equipes. A correção acontecia de forma manual, o grupo terminava e levantava a mão, então um monitor conferia se o código estava correto. Caso o código estivesse incorreto o monitor explicava o que faltava no código e os alunos tentavam resolver novamente para que todos tivessem a oportunidade de terminar os desafios.

Desse modo, foi perceptível que a oficina trouxe resultados satisfatórios, uma vez que a mesma promoveu a resolução de desafios em equipe envolvendo conceitos relacionados a lógica de programação. Observamos durante a realização da oficina o engajamento dos participantes e a busca pela melhor solução possível, bem como o anseio 
de superar as dificuldades para aprender os assuntos propostos que viessem solucionar os desafios aplicados.

Após análise dos resultados dos desafios, o método provou-se funcional e de fácil aplicação, visto que, a metodologia da Computação Desplugada, pode ser adaptada a qualquer ambiente e para uma gama diversa de públicos. A competitividade criada entre as equipes, fez com que as mesmas procurassem entender o conteúdo e tirar dúvidas durante a apresentação dos conceitos. Essas atitudes ajudaram os alunos a responderem os desafios mais rápido e de forma correta para assim vencer a competição.

\section{Considerações Finais}

O trabalho apresentou um relato de experiência do uso da Computação Desplugada e de elementos de Gamificação no planejamento e execução de uma oficina com o intuito de promover a aprendizagem da lógica de programação. Para apoiar o ensino foi proposto um quebra-cabeça, o "BlockCode".

A partir da observação da oficina percebemos o engajamento dos alunos na realização das atividades propostas. Este trabalho também traz como contribuição o fornecimento de uma nova estratégia para despertar o interesse e motivar aluno/professor, deste modo facilitando o processo de ensino aprendizagem.

A experiência mostrou-se de fácil aplicabilidade, podendo ser adaptada para qualquer ambiente e público alvo, entretanto necessita-se ainda de aprimoramentos para polir o método de aplicação.

\section{Referências}

ALVES, F. (2015). Gamification: como criar experiências de aprendizagem engajadoras. DVS Editora.

BEZERRA, Fábio de Lima; DIAS, Klissiomara. (2012) Programação de computadores no ensino fundamental: experiências com logo e scratch em escola pública.

BRAGA, M. C. G.; OBREGON, R. de F. A. Gamificação: estratégias para processos de aprendizagem. Congresso Nacional de Ambientes Hipermídias para Aprendizagem. 7o. Conahpa. São Luis, MA. 17 a 20 jun. 2015.

BELL, T., Witten, I, H. e Fellows, M. (2011). Computer Science Unplugged: Ensinando Ciência da Computação sem o uso do computador. Tradução coordenada por Luciano Porto Barreto.

DA SILVA, Andreza Regina Lopes et al. (2014) Gamificação na educação. Pimenta Cultural.

BORDINI, A., AVILA, C. M. O., CUNHA, M. M., CAVALHEIRO, S. A. C., FOSS, L., . AGUIAR, M. S. , REISER, R. H. S. (2016). Computação na Educação Básica no Brasil: o Estado da Arte. Revista de Informática Teórica e Aplicada , v. 23, n. 2, p. 210-238.

FARDO, M. L. (2013). A gamificação aplicada em ambientes de aprendizagem. RENOTE, 11.

FERreirA, A. C., MElHor, A., BARreto, J., de PAIVA, L. F., \& MATOS, E. (2015, October). Experiência prática interdisciplinar do raciocínio computacional em atividades de computação desplugada na educação básica. In Anais do Workshop de Informática na Escola (Vol. 21, No. 1, p. 256). 
HUIZINGA, J. Homo Ludens: o jogo como elemento da cultura. São Paulo: Perspectiva, 1980.

MARQUES, Diego Lopes et al. (2011) Atraindo alunos do ensino médio para a computação: Uma Experiência Prática de Introdução à Programação utilizando Jogos e Python. In: Anais do Workshop de Informática na Escola. 1138-1147.

NAGAI, W., \& IZEKI, C. (2016). As estratégias de gamificação da disciplina de Projeto e Análise de Algoritmos segundo o Modelo Dinâmico de Aprendizado baseado em Jogos. In Anais dos Workshops do Congresso Brasileiro de Informática na Educação (Vol. 5, No. 1, p. 1159).

SCAICO, Pasqueline Dantas et al. Ensino de programação no ensino médio: Uma abordagem orientada ao design com a linguagem scratch. Revista Brasileira de Informática na Educação, v. 21, n. 02, p. 92, 2013.

SOCIEDADE BRASILEIRA DE COMPUTAÇÃO. Referenciais de Formação em Computação: Educação Básica. Disponível em: http://www.sbc.org.br/noticias/10slideshow-noticias/1996-referenciais-de-formacao -e -computacao-educacao-basica $>$. Acesso em: 16 set. 2017.

SOUSA, R. V. de; Barreto L. P; Andrade, A; Abdalla, D. (2010) "Ensinando e aprendendo conceitos sobre a ciência da computação sem o uso do computador: Computação Unplugged!’. Práticas em Informática na Educação: Minicursos do Congresso Brasileiro de Informática na Educação, vol. 1, Número 1, 2010.

VALENTE, J. A. (2016). Integração do pensamento computacional no currículo da educação básica: diferentes estratégias usadas e questões de formação de professores e avaliação do aluno. Revista e-Curriculum, São Paulo, v.14, n.03, p. $864-897$ jul./set.2016. 